Volume 4

Issue 4 -- Health Disparities and Inequities: Part

Article 7

11-6-2017

\title{
Improving Chronic Pain Management Processes in Primary Care Using Practice Facilitation and Quality Improvement: The Central Appalachia Inter-Professional Pain Education Collaborative
}

Roberto Cardarelli

Sarah Weatherford

Jennifer Schilling

Dana King

Sue Workman

Wade Rankin

Juanita Hughes

Jonathan Piercy

Follow this and additional works at: https://aah.org/jpcrr

parfondep-Sallazmunity Health and Preventive Medicine Commons, Family Medicine Commons, Health and Medical Administration Commons, and the Primary Care Commons

Melissa Zook

Recommended Citation

Gakdake Zook M, Unger K, White $E$, Astuto B, Stover B. Improving chronic pain management processes in primary care using practice facilitation and quality improvement: the Central Appalachia Inter-Professional Pain Education Collaborative. J Patient Cent Res Rev. 2017;4:247-55. doi: 10.17294/2330-0698.1457

Published quarterly by Midwest-based health system Advocate Aurora Health and indexed in PubMed Central, the Journal of Patient-Centered Research and Reviews (JPCRR) is an open access, peer-reviewed medical journal focused on disseminating scholarly works devoted to improving patient-centered care practices, health outcomes, and the patient experience. 


\title{
Improving Chronic Pain Management Processes in Primary Care Using Practice
} Facilitation and Quality Improvement: The Central Appalachia Inter-Professional Pain Education Collaborative

\author{
Authors \\ Roberto Cardarelli, Sarah Weatherford, Jennifer Schilling, Dana King, Sue Workman, Wade Rankin, Juanita \\ Hughes, Jonathan Piercy, Amy Conley-Sallaz, Melissa Zook, Kendra Unger, Emma White, Barbara Astuto, \\ and Bobbi Stover
}




\title{
Improving Chronic Pain Management Processes in Primary Care Using Practice Facilitation and Quality Improvement: The Central Appalachia Inter-Professional Pain Education Collaborative
}

\author{
Roberto Cardarelli, DO, ${ }^{1}$ Sarah Weatherford, MSc, ${ }^{1}$ Jennifer Schilling, MPH, ${ }^{1}$ Dana King, MD, ${ }^{2}$ Sue \\ Workman, BSMS, ${ }^{2}$ Wade Rankin, DO,${ }^{1}$ Juanita Hughes, DO,${ }^{3}$ Jonathan Piercy, MD, ${ }^{4}$ Amy Conley-Sallaz, \\ $\mathrm{MD},{ }^{5}$ Melissa Zook, MD, ${ }^{6}$ Kendra Unger, MD, ${ }^{2}$ Emma White, RN, ${ }^{7}$ Barbara Astuto, RMA, ${ }^{8}$ Bobbi Stover, LPN $^{8}$ \\ ${ }^{1}$ Department of Family and Community Medicine, University of Kentucky College of Medicine, Lexington, KY; ${ }^{2}$ Department \\ of Family Medicine, West Virginia University, Morgantown, WV; ${ }^{3}$ East Kentucky Family Medicine Residency Program, \\ University of Kentucky June Buchanan Medical Clinic, Hindman, KY; ${ }^{4}$ East Kentucky Family Residency Program, \\ University of Kentucky North Fork Valley Community Health Center, Hazard, KY; ${ }^{5}$ University of Kentucky Family Medicine \\ Rural Track Residency Program, St. Claire Regional Medical Center, Morehead, KY; ${ }^{6}$ London Women's Care, London, \\ KY; ${ }^{7}$ Roane County Family Health Care, Spencer, WV; ${ }^{8}$ North Fayette Family Health Clinic, New River Health Association, \\ Fayetteville, WV
}

Purpose

Methods

Results

Conclusions

Keywords
With the increasing burden of chronic pain and opioid use, provider shortages in Eastern Kentucky and West Virginia have experienced many challenges related to chronic pain management. This study tested a practice facilitator model in both academic and community clinics that selected and implemented best practice processes to better assist patients with chronic pain and increase the use of interdisciplinary health care services.

Using a quasi-experimental design, a practice facilitator was assigned to each state's clinics and trained clinic teams in quality improvement methods to implement chronic pain tool(s) and workflow processes. Charts for 695 patients with chronic pain using opioids, from 8 randomly selected clinics in eastern Appalachia, were reviewed to assess for changes in clinic processes.

Statistically significant improvements were found in 10 out of 16 chronic pain best practice process measures. These included improved workflow implementation $(P<0.001)$, increased urine drug screen test orders $(P=0.001)$ and increased utilization of controlled medication agreements $(P=0.004)$. In total, 7 of 8 clinics significantly improved in at least one, if not all, selected and implemented process measures.

Our findings indicate that practice facilitation, standardization of workflows and formation of structured clinical teams can improve processes of care in chronic pain management and facilitate the use of interdisciplinary services. Future studies are needed to assess long-term patient-centered outcomes that may result from improved processes of chronic pain care. (J Patient Cent Res Rev. 2017;4:247-255.)

quality improvement, chronic pain, Appalachia, implementation, dissemination, primary care
$\mathrm{T}$ The burden of chronic pain and opioid use has been felt throughout the United States. More than 12.5 million people age 12 or older misused

Correspondence: Roberto Cardarelli, DO, 2195 Harrodsburg Road, Lexington, KY, 40504,

T: +1-859-323-3711, Email: rca234@uky.edu pain relievers in 2015..$^{1}$ Reactions vary among those who either defend or condemn the use of opioids for the management of chronic pain, a diagnosis that has nearly doubled over the past decade. ${ }^{2,3}$ Conscientious supporters of opioids remind us that there is a real threat of undertreating patients who experience pain and negatively impacting patients with mental disorders, causing a decline in overall function. ${ }^{4}$ Others contend that 
opiates are too easily abused, citing more than 20,100 U.S. deaths in 2015 related to pain medication use. ${ }^{5-8}$

Although the prescribing of opioids for chronic pain has increased in various specialties, it is primary care providers who shoulder $40 \%-50 \%$ of U.S. opioid prescriptions. ${ }^{7,8}$ This is likely due to the fact that two-thirds of U.S. primary care visits are pain related. ${ }^{9}$ Yet, chronic pain management goes beyond the prescribing of opiates and includes other first-line nonpharmacologic and pharmacologic options.

The National Pain Strategy, a response to a congressional mandate of the National Institutes of Health, cites several reasons for the problems seen in opioid prescribing practices. ${ }^{9}$ One is that patients, the public and providers lack knowledge regarding appropriate and safe management of chronic pain. ${ }^{9}$ With insufficient attention to pain management in medical education, primary care providers do not feel adequately trained for, and are often dissatisfied with, treating chronic pain patients, potentially leading to provider burn-out. ${ }^{10,11}$

Moreover, limited access to reimbursement for interprofessional care has been cited as a primary obstacle to addressing the opioid epidemic. ${ }^{12}$ The National Pain Strategy specifically highlights the need for increasing interprofessional care access, such as massage therapy, behavioral counseling and physical therapy, to reduce excessive dependence on opioids, and the authors concluded that coordination within the health care field and utilization of highquality team-based approaches will be necessary to effectively practice safe chronic pain management. ${ }^{13}$ The multifaceted recommendations in chronic pain management guidelines include risk stratification, behavioral evaluations, informed consents, diagnostic testing and many other processes. Therefore, to succeed in implementation of chronic pain guidelines, a team-based approach may ensure that effective and sustainable strategies are in place to deliver safe pain management.

In general, translating guidelines into practice is a lengthy process. It takes an estimated 17 years to proceed from initial discovery to clinical implementation. ${ }^{14}$ Barriers to the implementation of guidelines include provider-related factors (eg, lack of awareness, familiarity, interpretation or agreement). ${ }^{15}$ One model to help accelerate implementation of guidelines into practice is a practice facilitator/ facilitation (PF) model, also known as quality improvement (QI) coaching. PFs support improvement efforts in clinics and help build organizational capacity for QI. ${ }^{16}$ A systematic review found PF contributed to increases in delivery of preventive services through improved communication and relationships within clinics. ${ }^{17}$ Another meta-analytic review found practices receiving $\mathrm{PF}$ were three times as likely as control practices to implement guidelines. ${ }^{18}$ Studies also found the effects from PF to be sustained for as long as 12 months postintervention, ${ }^{19-22}$ with evidence of costeffectiveness. ${ }^{23}$ However, it remains unknown whether the effects of PF focused on using QI methods impacts clinical process measures in rural clinics caring for patients with chronic pain.

The Central Appalachia Inter-Professional Pain Education Collaborative (CAIPEC) was developed to improve practice performance in the treatment of chronic pain in rural primary care clinics in Kentucky and West Virginia through QI methods using PFs. Herein, we report the impact of the use of PFs in training and supporting teams in 8 rural clinics on QI methods with the goal of improving chronic pain process measures.

\section{METHODS Population}

A quasi-experimental pre/post implementation study was conducted in 2015-2016 to improve the clinic processes and care of patients with chronic pain. CAIPEC randomly recruited 20 primary care providers (physicians, physician assistants and nurse practitioners) across 8 clinics in Appalachia Kentucky and West Virginia. These clinics included 6 primary care clinics and 2 academic family medicine clinics. Eligible clinics were those that manage patients with chronic pain, defined as pain on most days lasting for at least 3 months, ${ }^{24}$ of which at least $20 \%$ of these patients were being managed with opioids. In addition, each provider included in the study had patients with chronic pain who were using opioids, whether managed by the provider or by a pain specialist.

The clinic population used in chart review assessments was comprised of patients who met 
eligibility criteria, namely, those at least 21 years of age with documented generalized chronic pain who had the following diagnosed conditions: 1) low back pain (ICD-9 724.2); 2) back pain NOS (ICD9 724.4); 3) chronic pain (ICD-9 338.29, 338.4); or 4) osteoarthrosis (ICD-9 715.00, 715.09, 715.90). In addition, these patients had to been seen for at least 3 visits within a 12 -month period by the providers participating in the study. Only patients who were currently managed with opioid medications as part of their chronic pain regimen were included in the chart review. This study was approved by both the University of Kentucky and West Virginia University institutional review boards.

\section{Team Development and Engagement}

A clinic champion was identified by each participating clinic, and a clinic QI team that included administrative and managerial office personnel, clinical management, nursing staff and health care providers was formed. A PF was available to each team and educated them in implementation processes and QI methods. There were two PFs working with their respective Kentucky and West Virginia clinics. The PFs attended training that was verified by the principal investigator based on the Agency for Healthcare Research and Quality (AHRQ) Practice Facilitation Handbook and associated competencies. These competencies included interpersonal skills to build support for and facilitate change, methods for accessing and using data to drive change, QI and change management strategies, and health information technology optimization..$^{25}$

\section{Implementation Framework}

The Promoting Action on Research Implementation in Health Services (PARiHS) framework ${ }^{26}$ served as the mechanism by which the clinics implemented the chronic pain guidelines. The clinics chose aspects of the PARiHS framework that provided guidance on proactive and productive team-based processes. The PARiHS framework represents essential determinants of successful implementation of research into practice on three core elements: 1 ) the perceived strength of the evidence; 2) the context of the environment in which the intervention is implemented; and 3) the processes by which the implementation is facilitated.

\section{Implementation Processes}

Initial team meetings involved reviewing the evidencebased chronic pain guidelines from the American Pain Society. ${ }^{27}$ Based on the PARiHS framework, discussions were focused on the perceived quality and applicability of the guideline. In addition, the team considered specific areas of potential improvement that they felt needed attention. These interactions and actions were documented in an implementation workbook accessible at http://www.cecentral.com/node/1266.

Subsequent meetings involved the PF instructing the clinic QI teams on implementation and QI processes, with meetings every $2-4$ weeks and specific tasks to be completed before the next meeting. Tasks included such things as choosing the clinic team for implementation, completing study instruments (ie, Organizational Readiness to Change, provider knowledge survey, team participation and functioning survey, and specific toolkit pages), choosing a guideline to follow (ie, opioid treatment guidelines or CAIPEC chronic pain webcasts) and, finally, choosing which QI process the clinic will implement.

To establish current processes and workflows, the PF and clinic QI team conducted a detailed walk-through of the clinic experience and identified potential areas for improvement. The teams then developed a new workflow

Process measure
Use of a clinic opioid policy
Use of a clinic workflow
Pain specific physical examination
UDS test within last 12 months
Controlled medication agreement in chart
Use of non-opioid adjuvant medication
Use of alternative therapies
Use of diagnostic testing
Referred to pain management
Referred to other specialists
Use of pain specific progress note
Goals were discussed with patient
A mood disorder tool used
A risk assessment tool used
A pain measure was documented
A functional assessment was used

Figure 1. Best practice process measures. 
based on these identified areas/processes. Clinic and team member responsibilities were then delineated and the clinic QI teams were educated on a Plan-Do-StudyAct (PDSA) QI cycle. ${ }^{28}$ Again, the PF instructed the teams through this iterative PDSA process. The number of completed PDSA cycles was based on achieving a clinic's particular process improvement goal, which was defined as implementing all aspects of the desired tasks for their chosen process change. Once all components of the new QI process were developed, a "go-live" date was established. Rapid assessments were further conducted to fine-tune the implementation process.

\section{QI Process Selection}

A "best practice" algorithm based on American Pain Society guidelines was developed as a menu of potential areas of improvement by the clinics (Figure 1). This includes such items as risk assessment, urine drug screening (UDS) and other recommended processes. Based on the baseline workflow assessments discussed previously, clinics chose one or more best practice process to implement for the project, allowing a pragmatic approach. That is, clinics selected the processes to improve upon based on the clinic's own specific needs identified in the earlier walk-through exercise (Table 1).

\section{Data Collection and Outcome Measures}

PFs conducted chart reviews for outcome measures (discussed below) for each clinic at baseline and again at 3 months after the implementation ("go-live") date. Clinic staff, and not the PF or research team, randomly selected charts if the patient met the aforementioned eligibility criteria. Charts were then verified for final inclusion criteria, as previously described, with subsequent data extraction by the PFs. Standardized data entry occurred utilizing web-based reporting through Research Electronic Data Capture (known as REDCap).

A sample size of 400 chart reviews was targeted based on estimated $20 \%$ improvement in process measures from baseline to postintervention ( 3 months) and a 0.01 intracluster correlation coefficient to account for clustering effects. Due to variation in the numbers of providers in each clinic and to account for potential attrition, our goal was to conduct 20 chart reviews per provider for both the baseline period and the 3-month postintervention period for a total of 800 chart reviews. Since not all providers had a sufficient number of patients meeting eligibility criteria described above, a total of 695 chart reviews were conducted for the study, still achieving sufficient power. Baseline and postintervention chart reviews were composed of two

Table 1. Sample of Process Interventions Chosen by One Participating Clinic

\begin{tabular}{l|l|l}
\hline Intervention & \multicolumn{1}{l}{ Summary description } & \multicolumn{2}{l}{ Process measure } \\
\hline $\begin{array}{l}\text { Clinic policy for controlled } \\
\text { medications }\end{array}$ & $\begin{array}{l}\text { Clinic implemented a controlled medications clinic protocol for new } \\
\text { patients stating opioids would not be prescribed on first visit. }\end{array}$ & $\begin{array}{l}\text { Use of a clinic opioid } \\
\text { policy }\end{array}$ \\
\hline $\begin{array}{l}\text { Physical therapy (PT) } \\
\text { quality reminder }\end{array}$ & $\begin{array}{l}\text { Clinic implemented a PT quality reminder in the electronic health } \\
\text { record system as a reminder to schedule PT appointments and } \\
\text { follow-up appointments. }\end{array}$ & $\begin{array}{l}\text { Use of integrative } \\
\text { therapies }\end{array}$ \\
\hline $\begin{array}{l}\text { Urine drug screen (UDS) } \\
\text { plan }\end{array}$ & $\begin{array}{l}\text { Medical assistant reviewed charts day prior to clinic visit. If chart } \\
\text { belonged to a chronic pain patient on opioids, the chart was flagged } \\
\text { for UDS if needed. Care team and provider executed the UDS. Clinic } \\
\text { nurse reviewed charts on Fridays to follow up on whether process } \\
\text { was completed. }\end{array}$ & $\begin{array}{l}\text { UDS test within last } \\
12 \text { months }\end{array}$ \\
\hline $\begin{array}{l}\text { Controlled medication } \\
\text { agreement in chart }\end{array}$ & $\begin{array}{l}\text { Medical assistant reviewed charts day prior to clinic visit. If chart } \\
\text { belonged to a chronic pain patient on opioids, the chart was flagged } \\
\text { for needed controlled medication agreement. Care team and provider } \\
\text { executed agreement as needed. Licensed practical nurse reviewed } \\
\text { charts on Fridays for follow-up on process. }\end{array}$ & $\begin{array}{l}\text { Controlled medication } \\
\text { agreement in chart }\end{array}$ \\
\hline $\begin{array}{l}\text { Pain Assessment and } \\
\text { Documentation Tool (PADT) }\end{array}$ & $\begin{array}{l}\text { Medical assistant reviewed charts day prior to clinic visit. If chart } \\
\text { belonged to a chronic pain patient on opioids, the chart was flagged } \\
\text { for needed PADT. Care team and provider executed PADT, referencing } \\
\text { the "Potential Aberrant Drug-Related Behavior" section. Licensed } \\
\text { practical nurse reviewed charts on Fridays for follow-up on process. }\end{array}$ & $\begin{array}{l}\text { A risk assessment } \\
\text { tool used }\end{array}$ \\
\hline
\end{tabular}


independent cohorts (ie, "samples") and not linked to the same patients. Hence, these samples were independent from one another.

The intent of the study was to assess changes in process measures related to chronic pain management and not patient clinical outcomes (ie, pain levels), since pre/post assessments were only 3 months apart. A comprehensive list of chronic pain process measures was assessed for each clinic regardless of the best practice process that was actually implemented by the clinic. The outcomes, aligned with the National Pain Strategy overarching plan, included presence of a clinic opioid policy, clinic workflow, a physical exam, UDS ordered within last 12 months, a controlled medication agreement, use of nonopioid medications and integrative therapies, use of diagnostic testing, referral to specialists, use of pain-specific notes (ie, the Pain Assessment and Documentation $\mathrm{Tool}^{29}$ ), and whether goals were discussed with the patient. In addition, documentation of measured pain and use of mood disorder (GAD-7 ${ }^{30}$ and PHQ-9 ${ }^{31}$ ), risk (Opioid Risk Tool ${ }^{32}$ ) and functional assessment (Pain Disability Index ${ }^{33}$ ) tools were reviewed. Other tools and resources that clinics could choose from can be found on the CAIPEC study website.

\section{Statistical Analyses}

Counts and frequencies were used to assess each process measure. Summative data were collated for all providers and clinics. Chi-squared analyses were performed to assess the pre/post impact of the QI procedures on each process. All analyses were conducted using Statistical Package for the Social Sciences (SPSS) Version 21 (IBM Corporation, Armonk, NY), and a 0.05 level of significance was adopted.

\section{RESULTS}

\section{Provider Characteristics}

Of the 20 providers, $75 \%$ were physicians and more than half reported they had practiced for 6-15 years; 90\% were registered with the U.S. Drug Enforcement Administration, and $80 \%$ reported being licensed to prescribe schedule 2 and schedule 3 medications (as advanced practice providers were included in the study). In addition $75 \%$ of providers reported writing at least one opioid prescription in the past 12 months, and 75\% managed between 16 and 60 patients with chronic pain (Table 2). All providers and clinics that started the study were accounted for at study completion.
Table 2. Provider Participant $(\mathrm{N}=20)$ Characteristics

\begin{tabular}{lc}
\hline Characteristic & $\mathbf{n}(\%)$ \\
\hline Health professional category & \\
$\quad$ Physician & $15(75 \%)$ \\
Advanced practice nurse & $1(5 \%)$ \\
Physician assistant & $4(20 \%)$ \\
DEA-registered & \\
Yes & $18(90 \%)$ \\
No & $2(10 \%)$ \\
Licensed to prescribe schedule II/III medications & \\
Yes & $16(80 \%)$ \\
No & $4(20 \%)$ \\
Written $\geq 1$ opioid prescription in last year & \\
Yes & $15(75 \%)$ \\
No & $5(25 \%)$ \\
Number of years in practice & \\
$\leq 5$ & $4(20 \%)$ \\
$6-10$ & $9(45 \%)$ \\
$11-15$ & $3(15 \%)$ \\
$16-20$ & $1(5 \%)$ \\
$21-25$ & $1(5 \%)$ \\
$>25$ & $2(10 \%)$ \\
Number of patients managed for chronic pain & \\
$\leq 5$ & $1(5 \%)$ \\
$6-15$ & $3(15 \%)$ \\
$31-60$ & $6(30 \%)$ \\
$61-100$ & $9(45 \%)$ \\
$>100$ & $1(5 \%)$ \\
\hline
\end{tabular}

DEA, U.S. Drug Enforcement Administration.

\section{Process Outcomes}

Overall, there were statistically significant improvements in 10 of 16 process measures across all 8 clinics (Table 3 ). While the 8 clinics targeted an average of 2.4 (range: 1-5) processes on which to improve during the study period, they in fact improved in 4.6 of 16 (range: 2-9) possible processes. Compared to baseline measures there was a $91 \%$ improvement in workflow implementation, a $12.9 \%$ increase in UDS tests ordered and a $10.7 \%$ increase in charted controlled medication agreements. Significant increases also were observed in the use of adjuvant medications (11.8\%), integrative (massage, physical or behavioral) therapies $(8.5 \%)$, and referrals to other specialists (16.1\%). Substance abuse risk assessments also increased (11.9\%), as did assessments of behavioral disorders $(8.2 \%)$, pain level 


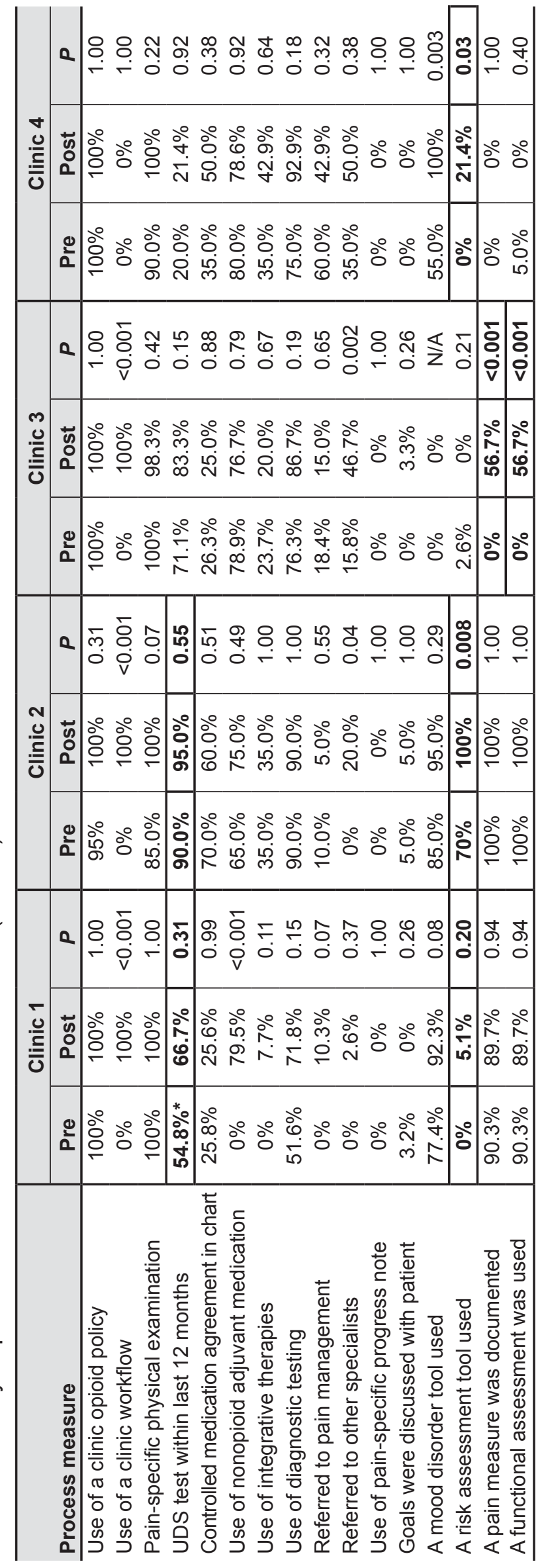

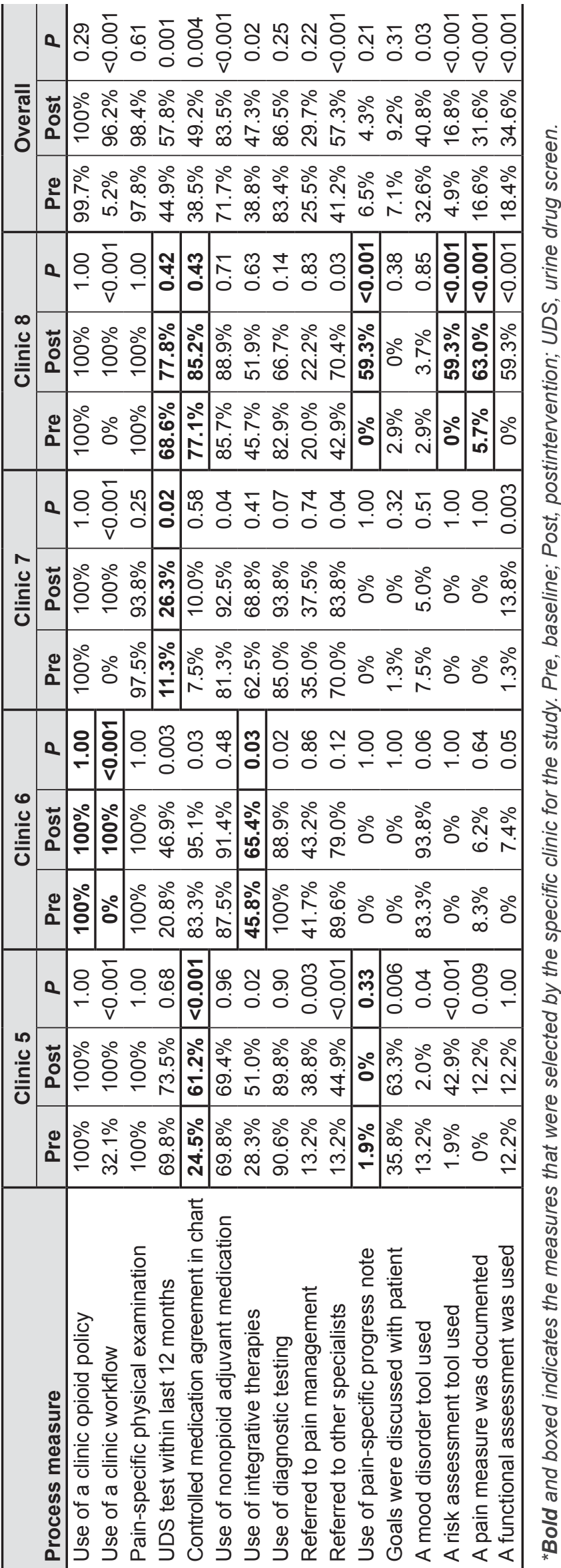


$(15 \%)$ and function $(16.2 \%)$. In fact, 7 of 8 clinics significantly improved in at least one, if not all, the process measures for which they chose to intervene (see boxed data in Table 3).

\section{DISCUSSION}

The use of opioid analgesics for the treatment of chronic pain remains a contentious issue. This reflects a paradigm shift since the late 1980s when the undertreatment of pain became a public health concern, ${ }^{34}$ which subsequently catalyzed our current opioid epidemic..$^{35}$ While the fears of harm - abuse, misuse and overdose - are genuine, many patients claim that opioids benefit them considerably. The outcomes of this project show that by using clinic QI team-based approaches with practice facilitation, we can positively affect clinic performance and the uptake of interdisciplinary health care services, including referrals to pain specialists and other integrative therapies such as physical therapy, behavioral health and massage therapy, in chronic pain management.

The burden of chronic pain management is often perceived by the primary care provider as his or her sole responsibility. This isolated approach can lead to provider burnout, stereotyping of pain patients and a low sense of confidence in managing patients with chronic pain. Specifically, such stereotyping can include lack of confidence in patient self-management and a stronger focus on psychological factors, which greatly affects the patient-centered approach to chronic pain management. ${ }^{11}$ A team-based approach distributes the actions required for comprehensive care by using the entire range of staff and providers within the clinic.

The CAIPEC implementation approach, with guidance by PFs, steered clinics to form structured clinical teams to improve their care processes for patients with chronic pain. The acceleration in clinic transformation by using PFs is based on improved organizational capacity for QI. ${ }^{16}$ Systematic reviews and other studies also have shown PF models to increase delivery of services by improving communication with sustainable effects. ${ }^{17,18}$ With the availability of training modules ${ }^{25}$ and certifying programs, it is possible for selected clinic staff to have their roles redefined to include PF training and competencies. Hence, this approach may be applicable to many community clinics, as current positions can be redefined without the need for hiring additional staff. Evidence suggests that practice facilitation is cost-effective in the long run. ${ }^{23}$

QI interventions within the primary care setting have shown the potential to benefit patients with chronic pain. However, high workloads in primary care offices serve as a common barrier to successfully implement such changes. ${ }^{36}$ With the use of a collaborative care intervention, Dobscha et al discovered significant improvements among primary care patients with chronic pain. ${ }^{36}$ The collaborative care intervention involved case management and internists who developed tailored care plans based on specific patient assessments, resulting in significant improvements in pain-related disability and pain intensity. This is promising, as our study only measured changes in process measures and not patient outcomes such as pain level. We were limited by a short follow-up period (3 months) after implementation, which is amenable to assessing changes in clinic processes but not patientcentered outcomes.

While our study's primary aim was to assess the impact of PF using QI methods to improve chronic pain management processes, there are other findings worth noting. Our study was conducted in two states (Kentucky and West Virginia) with provider regulations on opioid prescribing by their respective medical boards. ${ }^{37,38}$ Yet, baseline assessments of these clinics showed large gaps in expected care processes. For example, 4 of 8 clinics had less than $50 \%$ of patients with a controlled medication agreement and 3 of 8 clinics had less than $50 \%$ with a UDS in the previous 12 months. Therefore, these gaps reflect possible risk to providers and may serve as an incentive to participate in new approaches to practice, despite the inconveniences caused by such changes.

\section{Limitations}

Several limitations should be noted in our quasiexperimental design. Quasi-experimental designs are frequently used to evaluate interventions. Unlike a randomized control trial, the observed changes may be accounted for by other trends that were not studied. ${ }^{39}$ CAIPEC was conducted in rural Appalachia, and its results may not be generalizable to other regions in the United States. 
The use of a PF may have limited the generalizability of the intervention, as most primary care clinics do not have this resource or capability. Nonetheless, we believe that clinics have an opportunity to repurpose selected staff members to develop PF skills based on available modules and training programs. Moreover, the benefits demonstrated in our study serve as an impetus for organizations to justify funding such positions. Training can be found within The Practice Facilitation Handbook: Training Modules for New Facilitators and Their Trainers, published by AHRQ, or online at https:// pcmh.ahrq.gov/page/practice-facilitation.

We also acknowledge that since use of PF was part of the intervention, we were unable to assess whether QI methods alone would have yielded the same results. Since we only evaluated process changes over a 3-month period, we are unable to assess patient-centered outcomes and sustainability of our intervention.

\section{CONCLUSIONS}

This study demonstrated that a practice facilitation model may enhance quality improvement method implementation. Future multifaceted studies should focus on population- and practice-level interventions that assess both patient and provider behaviors and related outcomes. Such interventions are needed to increase the awareness of opioid risk and appropriate management of chronic pain through a team-based approach.

\section{Patient-Friendly Recap}

- The practice of managing chronic pain through prescription opioids is contentious.

- Rural clinics experiencing provider shortages often struggle to take a comprehensive approach to pain management, potentially resulting in overuse of opioids.

- The authors studied whether the use of practice facilitators - personnel trained in chronic pain tools and workflow processes — would help enact quality improvement methods within clinics.

- They found that interdisciplinary collaboration of care increased during the intervention and that numerous best practice measures improved.

\section{Conflicts of Interest}

The authors have no involvement in any organization with financial or nonfinancial interest in the subject matter or materials discussed in this manuscript.

\section{Funding Sources}

This work was supported by the Independent Grants for Learning and Change through the Pfizer Consortium [Grant No. 16364911].

\section{References}

1. Hughes A, Williams MR, Lipari RN, Bose J, Copello EAP, Kroutil LA. Prescription drug use and misuse in the United States: results from the 2015 National Survey on Drug Use and Health. National Survey on Drug Use and Health Data Review. September 2016. Retrieved from http://www. samhsa.gov/data/ on June 26, 2017.

2. Daubresse M, Chang HY, Yu Y, et al. Ambulatory disgnosis and treatment of nonmalignant pain in the United States, 2000-2010. Med Care. 2013;51:870-8. CrossRef

3. Centers for Disease Control and Prevention; National Center for Injury Prevention and Control; Division of Unintentional Injury Prevention. Opioid overdose: understanding the epidemic. https://www.cdc.gov/drugoverdose/epidemic/ index.html. Accessed June 26, 2017.

4. Tang NK, Crane C. Suicidality in chronic pain: a review of the prevelance, risk factors and psychological links. Psychol Med. 2006;36:575-86. CrossRef

5. Rudd RA, Seth P, David F, Scholl L. Increases in drug and opioid-involved overdose deaths - United States, 20102015. MMWR Morb Mortal Wkly Rep. 2016;65:1445-52. CrossRef

6. Dart RC, Surratt HL, Cicero TJ, et al. Trends in opioid analgesic abuse and mortality in the United States. $N$ Engl J Med. 2015;372:241-8. CrossRef

7. Okie S. A flood of opioids, a rising tide of deaths. $N$ Engl J Med. 2010;363:1981-5. CrossRef

8. Centers for Disease Control and Prevention; National Center for Injury Prevention and Control; Division of Unintentional Injury Prevention. Opioid overdose: prescribing data. https://www.cdc.gov/drugoverdose/data/ prescribing.html. Accessed June 26, 2017.

9. Office of the Assistant Secretary for Health, U.S. Department of Health and Human Services. National Pain Strategy: a comprehensive population health-level strategy for pain. https://iprcc.nih.gov/docs/HHSNational_Pain_Strategy. pdf. Accessed June 26, 2017.

10. Potter M, Schafer S, Gonzalez-Mendez E, et al. Opioids for chronic nonmalignant pain. Attitudes and practices of primary care physicians in the UCSF/Stanford Collaborative Research Network. J Fam Pract. 2001;50:145-51.

11. Upshur CC, Luckmann RS, Savageau JA. Primary care provider concerns about management of chronic pain in community clinic populations. J Gen Intern Med. 2006;21:652-5. CrossRef

12. Gordon DB, Dahl JL. Quality improvement challenges in pain management. Pain. 2004;107(1-2):1-4. CrossRef

13. National Institute of Health, Interagency Pain Research Coordinating Committee. National Pain Strategy outlines 
action for improving pain care in America. Published March 18, 2016. https://iprcc.nih.gov/National_Pain_Strategy/ NPS Main.htm. Accessed June 26, 2017.

14. Morris ZS, Wooding S, Grant J. The answer is 17 years, what is the question: understanding time lags in translational research. J R Soc Med. 2011;104:510-20. CrossRef

15. Cabana MD, Rand CS, Powe NR, et al. Why don't physicians follow clinical practice guidelines? A framework for improvement. JAMA. 1999;282:1458-65. CrossRef

16. Nutting PA, Crabtree BF, StewartEE, et al. Effect of facilitation on practice outcomes in the National Demonstration Project model of the patient-centered medical home. Ann Fam Med. 2010;8 Suppl 1:S33-44, 92. CrossRef

17. Nagykaldi Z, Mold JW, Aspy CB. Practice facilitators: a review of the literature. Fam Med. 2005;37:581-8.

18. Baskerville NB, Liddy C, Hogg W. Systematic review and meta-analysis of practice facilitation within primary care settings. Ann Fam Med. 2012;10:63-74. CrossRef

19. Dietrich AJ, Sox CH, Tosteson TD, Woodruff CB. Durability of improved physician early detection of cancer after conclusion of intervention support. Cancer Epidemiol Biomarkers Prev. 1994;3:335-40.

20. Hogg W, Baskerville N, Nykiforuk C, Mallen D. Improved preventive care in family practices with outreach facilitation: understanding success and failure. J Health Serv Res Policy. 2002;7:195-201. CrossRef

21. Hogg W, Lemelin J, Graham ID, et al. Improving prevention in primary care: evaluating the effectiveness of outreach facilitation. Fam Pract. 2008;25:40-8. CrossRef

22. Stange KC, Goodwin MA, Zyzanski SJ, Dietrich AJ. Sustainability of a practice-individualized preventive service delivery intervention. Am J Prev Med. 2003;25:296-300. CrossRef

23. Hogg W, Baskerville N, Lemelin J. Cost savings associated with improving appropriate and reducing inappropriate preventive care: cost-consequences analysis. BMC Health Serv Res. 2005;5(1):20. CrossRef

24. Fayaz A, Croft P, Langford RM, Donaldson LJ, Jones GT. Prevalence of chronic pain in the UK: a systematic review and meta-analysis of population studies. BMJ Open. 2016;6:e010364. CrossRef

25. Knox L, Brach, C. The Practice Facilitation Handbook: Training Modules for New Facilitators and Their Trainers. Rockville, MD: Agency for Healthcare Research and Quality, 2013, AHRQ Publication No. 13-0046-EF.
26. National Collaborating Centre for Methods and Tools. PARiHS framework for implementing research into practice. Published March 30, 2011; updated September 18, 2017. http://www.nccmt.ca/knowledge-repositories/search/85.

27. Chou R, Fanciullo G, Fine PG, et al. Clinical guidelines for the use of chronic opioid therapy in chronic noncancer pain. J Pain. 2009;10:113-30. CrossRef

28. Institute for Healthcare Improvement. Tools: PlanDo-Study-Act (PDSA) worksheet. http://www.ihi.org/ resources/Pages/Tools/PlanDoStudyActWorksheet.aspx. Accessed June 26, 2017.

29. Passik SD, Kirsh KL, Whitcomb L, et al. A new tool to assess and document pain outcomes in chronic pain patients receiving opioid therapy. Clin Ther. 2004;26:552-61. CrossRef

30. Spitzer RL, Kroenke K, Williams JB, Löwe B. A brief measure for assessing generalized anxiety disorder: the GAD-7. Arch Intern Med. 2006;166:1092-7. CrossRef

31. Kroenke K, Spitzer RL, Williams JB. The PHQ-9: validity of a brief depression severity measure. J Gen Intern Med. 2001;16:606-13. CrossRef

32. Webster LR, Webster RM. Predicting aberrant behaviors in opioid-treated patients: preliminary validation of the Opioid Risk Tool. Pain Med. 2005;6:432-42. CrossRef

33. Pollard CA. Preliminary validity study of the pain disability index. Percept Mot Skills. 1984;59:974. CrossRef

34. Nicholson B, Passik SD. Management of chronic noncancer pain in the primary care setting. South Med J. 2007;100:1028-36. CrossRef

35. Manchikanti L, Helm S 2nd, Fellows B, et al. Opioid epidemic in the United States. Pain Physician. 2012;15:ES9-38.

36. Dobscha SK, Corson K, Perrin NA, et al. Collaborative care for chronic pain in primary care: a cluster randomized trial. JAMA. 2009;301:1242-52. CrossRef

37. West Virginia Board of Medicine. Management of Pain Act. https://wvbom.wv.gov/Mange_Intractable_Pain.asp. Accessed June 26, 2017.

38. Kentucky Board of Medical Licensure. Prescribing/substance abuse screening \& treatment resources. http://kbml.ky.gov/ prescribing-substance-abuse/Pages/default.aspx. Accessed June 26, 2017.

39. Harris AD, McGregor JC, Perencevich EN, et al. The use and interpretation of quasi-experimental studies in medical informatics. J Am Med Inform Assoc. 2006;13:16-23. CrossRef

(C) 2017 Aurora Health Care, Inc. 